\title{
Permeability and stability of soilbags in slope protection structures
}

\author{
Bo Zhou ${ }^{1,2}$, Hongyu Wang ${ }^{1 *}$, Xiaodong Wang ${ }^{1}$, Jinghui Ji ${ }^{1}$ \\ ${ }^{1}$ College of Civil and Hydraulic Engineering, Ningxia University, Yinchuan 750021, China \\ ${ }^{2}$ Yinchuan Energy Institute, Yinchuan 750105, China
}

Corresponding Author Email: zbzb.8160@163.com

https://doi.org/10.18280/ijht.360341

Received: 5 February 2018

Accepted: 29 May 2018

\section{Keywords:}

soilbag, filtration characteristic, permeability coefficient, gradient ratio, seepage pressure

\begin{abstract}
Farmland drainage ditch slumps restrict recirculation of water resources in the irrigation area of Ningxia in China. To address this problem, soilbags are applied for farmland drainage ditch slope protection, because of their double efficacy in solid slope collapse prevention and water purification. Variations in the mean flow rate, weight of soil passing through the geotextile, and gradient ratio were analyzed based on filtration criteria. Filtration and permeability performance of soilbag technology was studied using a clogging and permeability test, which was performed with gradient ratio and penetration test instruments. Different hydraulic gradients and building structures were tested. The clogging test shows that a rapid increase in the hydraulic gradient can decrease the permeability coefficient of the soil-geotextiles system by $77.99 \%$, lower filtration, reduce soil content per unit area, and increase leakage. The influence of the size of the soilbag (two different sizes were tested) and their arrangement was investigated. Penetration tests demonstrated that an overlapped structure with staggered joints significantly reduced the overall permeability coefficient. With a smaller bag size, the permeability coefficient of structure was larger. The permeability coefficient ratio with different bag arrangements was as high as $90.75 \%$. The results indicate that flow through a soilbag structure is governed solely by the gaps between neighboring containers and that flow through the soil in the containers can be neglected. The arrangement of soilbags thus strongly affects the permeability of the structure. Combining these results with a masonry plan for slope protection in engineering applications with soilbags, the equivalent permeability coefficient of the soilbag slope protection increased $100 \%$ and seepage pressure decreased $50 \%$, which effectively improved the stability of the slope protection. These results provide a theoretical basis for further engineering applications.
\end{abstract}

\section{INTRODUCTION}

Recently, soilbag techniques have been rapidly developing in the field of geosynthetic materials research and application. Soilbags are made of soil, sand, gravel, construction waste, or other materials filled into geotextile bags. These soilbags can be paved in a given arrangement to reinforce a foundation. At present [1-2], soilbag technology has been widely applied in civil engineering, water conservancy, port maintenance, road traffic, and other large projects [3-6]. Guanglu Li's research group applied polypropylene geotextile bags in terraced field ridges and walls and studied the economic benefit, failure mode and stability of this method [7-9]. However, the application of soilbags in agricultural drainage channel regulation and in farmland drainage ditch slope reinforcement has not been well studied [10-12]. In northwest China, where drainage of excess water in farmland irrigation areas is a common issue, the largest problem comes from seepage deformation caused by the collapse of slope and channel flow resulting from scour and alternating wet-dry and freezingthawing cycles. Soilbags have the dual functions of filtration for drainage and protection through reinforcement. Other research shows that soilbags can alleviate frost heave deformation [13]. At the same time, the biggest problems are seepage deformation caused by slope collapse and channel flow that cause slope scouring, alternating wet-dry and freezing-thawing cycles, and the influence of natural environment factors [14]. In the northern Ningxia Yellow River irrigation area, grass soil pile slope protection is widely used. After 2 to 3 years, local slip will occur in such constructions, leading to possible slope collapse. This technology can be improved with dry stone paving; however, there is a lack of stone and the engineering cost is high. Therefore, soilbags used for farmland drainage ditches are a better option, as they provide both a sturdy slope and water purification.

In soilbag use, clogging is the most important criteria for ensuring that the geotextiles can be used long-term. To determine whether geotextiles meet the desired clogging criteria, a gradient ratio test is needed. Tang et al. (2013) [15] used gradient ratio tests for filtration parameters along with the change in tensile strain of the geotextiles. Chen et al. (2006) [16] simulated fine-grained soil particles in an arch structure for a stability filtration test, demonstrating that the use of large-aperture geotextile filters reduced siltation. Shu et al. (2002) [17] changed the gradient ratio by changing the hydraulic grade. $\mathrm{Hu}$ et al. (2002) [18] studied the operating period of geotextiles in an integrated filtration test as part of research for the Shenzhen River regulation project, which provided strength loss data during long-term intensity attenuation. Hsin-Yu et al. (2001) [19] obtained geotextile gradient ratios and permeability coefficients using a gradient 
ratio test. They demonstrated that the gradient ratio test can be used as a standard for measuring the parameters of a filter system that includes geotextiles. Soilbags in farmland slope protection engineering may be filled with river bank soil cleared from bottom silt. Therefore, siltation research on the filtration ability of a soil-fabric system is particularly important.

The permeability coefficient is an important parameter in the calculation and analysis of fixed slope stability and seepage. For bank revetment structures, permeability is proportional to stability [20]. Liu et al. (2013) [21] used soilbags to strengthen an expansive soil slope, showing good resistance of slope deformation. Very high permeability and friction coefficients were found between layers (Recio, 2008) when studying the permeability coefficient of soilbags in different arrangements. The permeability coefficient was indicated to be the most important factor in the gaps between soilbags. To date, research on the permeability coefficients of entire soilbag structures is lacking, and experimental studies on the permeability coefficients and seepage pressures of soilsoilbag combination slopes are scarce.

In this paper, soilbag technology was used for farmland drainage ditch slope protection in the irrigation area of Ningxia province in China. The permeability coefficient and the filtration ability of the entire structure were assessed. The equivalent permeability coefficients of soil-soilbag combination slopes and their effects on the seepage pressures were investigated. This research applied soilbag technology in the field and provides basis parameters for design.

\section{MATERIALS AND METHODS}

\subsection{Soil and geotextile}

Soil was taken from the ShengLi ditch slope in Qingtongxia Yesheng town of Ningxia. Soil samples were taken at a depth of $50 \mathrm{~cm}$ from the surface with an annular sword $(\varphi 61.8 \mathrm{~mm} \times 20 \mathrm{~mm})$. A density test was performed on undisturbed soil in the annular sword. The soil was then sieved through a $2 \mathrm{~mm}$ mesh, air dried, crushed, and mixed to make indoor test soil samples. Particle distribution was analyzed. An STYS-1 computer was used to measure the liquid limit, plastic limit, and plasticity index of the soil samples. A variable head method was used to test the permeability coefficients of undisturbed soil samples. A DZY-II type multi-function electric compaction was used to measure the maximum dry density and optimum moisture content of the soil sample. The physical properties for the soil samples are given in Table 1. For the experiments, black polypropylene non-woven fabric geotextiles from the Shandong Yizheng Haicheng Nonwoven Material Corporation were used. The physical properties of the geotextile are presented in Table 2.

Table 1. Physical properties of test soils

\begin{tabular}{|c|c|c|c|c|c|c|c|c|c|c|}
\hline \multicolumn{4}{|c|}{$\begin{array}{c}\text { Soil particle composition / } \\
\%\end{array}$} & \multirow{2}{*}{$\begin{array}{c}\text { Density } \\
\text { Natural } \\
\text { Density/ } \\
\mathrm{g} \cdot \mathrm{cm}^{-3}\end{array}$} & \multicolumn{3}{|c|}{$\begin{array}{c}\text { LI Test / } \\
\%\end{array}$} & \multicolumn{2}{|c|}{ Permeability coefficient } & \multirow{2}{*}{$\begin{array}{c}\text { Compaction test } \\
\text { Optimum moisture } \\
\text { content } \\
1 \%\end{array}$} \\
\hline $\begin{array}{c}\text { Less } \\
\text { than } \\
0.075 \\
\mathrm{~mm}\end{array}$ & $\begin{array}{c}0.075- \\
0.315 \\
\mathrm{~mm}\end{array}$ & $\begin{array}{c}0.315-1 \\
\mathrm{~mm}\end{array}$ & $\begin{array}{l}1-2 \\
\mathrm{~mm}\end{array}$ & & $\begin{array}{l}W_{L} \\
1 \%\end{array}$ & $\begin{array}{l}W_{P} \\
1 \%\end{array}$ & $\begin{array}{l}I_{P} \\
1 \%\end{array}$ & $\begin{array}{l}\text { Vertical } \\
/ \mathrm{cm} \cdot \mathrm{s}^{-1}\end{array}$ & $\begin{array}{c}\text { Maximal dry } \\
\text { density } / \mathrm{g} \cdot \mathrm{cm}^{-3}\end{array}$ & \\
\hline 44.63 & 33.95 & 15.35 & 6.07 & 1.717 & 16.3 & 30.5 & 14.2 & $4.63 \times 10^{-5}$ & 1.799 & 15.32 \\
\hline
\end{tabular}

Table 2. Physical properties of test geotextile

\begin{tabular}{|c|c|c|c|c|c|c|c|c|}
\hline \multirow[t]{2}{*}{ Characteristic } & \multirow{2}{*}{$\begin{array}{l}\text { Mass per unit } \\
\text { area } / \mathrm{g} \cdot \mathrm{m}^{2}\end{array}$} & \multirow{2}{*}{$\begin{array}{c}\text { Thickness } \\
/ \mathrm{mm}\end{array}$} & \multicolumn{2}{|c|}{$\begin{array}{l}\text { Breaking strength } \\
/ \mathrm{kN} \cdot \mathrm{m}^{-1}\end{array}$} & \multicolumn{2}{|c|}{$\begin{array}{c}\text { Elongation } \\
1 \%\end{array}$} & \multirow{2}{*}{$\begin{array}{c}\text { CBR burst } \\
\text { testing } \\
/ \mathrm{kN} \\
\end{array}$} & \multirow{2}{*}{$\begin{array}{c}\text { Transverse } \\
\text { permeability } \\
/ \mathrm{cm} \cdot \mathrm{s}^{-1}\end{array}$} \\
\hline & & & Portrait & Landscape & Portrait & Landscape & & \\
\hline $\begin{array}{c}\text { Black } \\
\text { polypropylene }\end{array}$ & 122 & 0.6 & 5.58 & 4.52 & 45 & 70 & 0.55 & $1.9 \times 10^{-1}$ \\
\hline
\end{tabular}

\subsection{Test method and instruments}

\subsubsection{Soil-fabric system for the filtration test}

Filtration tests were performed according to standard test procedures(T1145-2006). The gradient ratio test apparatus was constructed as shown in Figure 1, with an instrument section of $100 \mathrm{~mm}$ by $100 \mathrm{~mm}$. Upper and lower containers were included, with a screw for clamping the geotextile in place. Six piezometric tubes were fixed on the measuring pressure plate, with a measurement scale of $1 \mathrm{~mm}$. The water injection and outlet included an overflow device to ensure constant head. Once the test instrument was ready, the soaked geotextiles were placed in the instrument. The soil was divided evenly into four layers in the instrument, according to the standard dry density of $1.71 \mathrm{~g} / \mathrm{cm} 3$. Each layer was tapped with a wooden hammer to $25 \mathrm{~mm}$ thickness. Permeable slabs supported the geotextiles and were placed above the filled soil. Before the test, the piezometric tubes were closed at locations $1-6$, with the water supply entering slowly from the bottom of the instrument. When the water level reached $5 \mathrm{~mm}$ above the soil, the system was soaked at saturation for $5 \mathrm{~h}$. Water was then injected from above the hole, and the water level regulated. Air holes were closed after venting gas, and piezometric tubes 1-6 were opened. After the readings stabilized, measurements were taken every hour for 24 hours. The total head was set to $40 \mathrm{~cm}, 70 \mathrm{~cm}$, and $110 \mathrm{~cm}$, with corresponding hydraulic gradients of $i=4,7$, and 11 . Two hydraulic gradient change methods were investigated. In the first, i was gradually increased to 4,7 , or 11 , while in the second, i increased directly to 11 . The lower container in the test instrument allowed for collection of the seepage water for soil content analysis after drying and weighing. After each test, the fabric was removed, dried, and weighed to analyze the surface soil content and internal soil mass.

GR refers to the hydraulic gradient ratio of geotextile specimens to above $25 \mathrm{~mm}$ and of soil sample fabric from 25 to $75 \mathrm{~mm}$ in the experiment, as calculated by Formula (1). A larger GR indicates a worse fabric filter [22], as it would 
experience easy clogging.

$$
G R=\frac{H_{1-2} /\left(L_{1}+\delta\right)}{H_{2-3} / L_{2}}
$$

where $H_{1-2}$ is the water head in the piezometric tube between 1 and $2(\mathrm{~mm}) ; H_{2-3}$ is the water head between 2 and $3(\mathrm{~mm}) ; L_{l}$ and $L_{2}$ are the seepage path lengths $(\mathrm{mm})$; and $\delta$ is the geotextile thickness $(\mathrm{mm})$.

This test determines the soil-geotextile filter properties of permeability coefficient, gradient ratio $(G R)$, soil content per unit area $(\mu)$, and soil quantity.

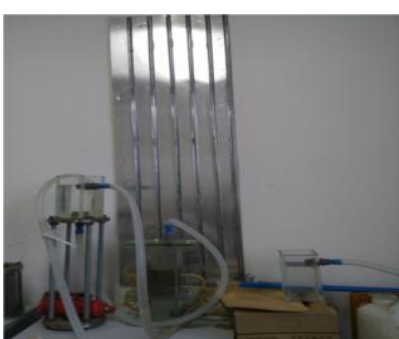

(a) Apparatus setting



(b) Schematic diagram (Units: $\mathrm{mm}$ )
Figure 1. Apparatus for gradient ratio tests

2.2.2 Determination of permeability coefficients for soilbag structures

In this paper, the constant water head test method is used, the permeability of large structures was measured(Figure2), it has same principles as traditional laboratory methods ,but this test instrument can simulated realistic working condition.

Two soilbag sizes were made using the black polypropylene: $30 \times 40 \times 10 \mathrm{~cm}$ and $20 \times 30 \times 8 \mathrm{~cm}$. In order to fully utilize the bag body tension, each bag was filled $80 \%$ at a filling density of $1.71 \mathrm{~g} / \mathrm{cm}^{3}$.

The penetration test instrument was constructed of a large test box with constant head permeability. The box body size was $140 \times 60 \times 140 \mathrm{~cm}$ (Figure 2). To decrease the side wall effect, the soilbag contact surface was treated with a petroleum oil filling and compacting process. The soilbag wall structure consisted of a homogeneous porous medium. The seepage coefficient of permeability from Darcy's law was used to solve for $\mathrm{k}$, as shown in Formula (2).

$$
\mathrm{k}=\frac{Q L}{H A}
$$

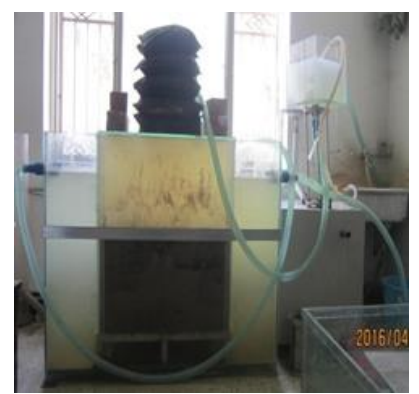

(a) Apparatus

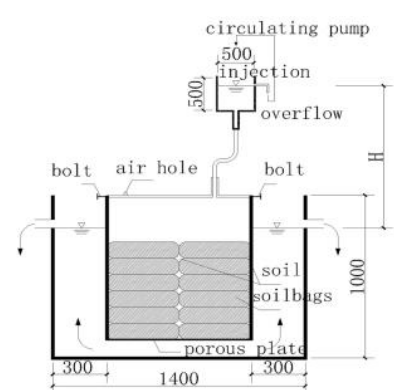

(b) Schematic(Units:mm)
Figure 2. Apparatus for permeability tests

where $Q$ is the seepage discharge $\left(\mathrm{cm}^{3} \cdot \mathrm{s}^{-1}\right) ; A$ is the soilbag wall cross sectional area $\left(\mathrm{cm}^{2}\right) ; H$ is the head $(\mathrm{cm})$; and $L$ is the soilbag wall height $(\mathrm{cm})$;

To study the influence of different bags sizes and arrangements on the permeability coefficient, tests were performed at different hydraulic gradients. Permeability coefficients were measured for eight soilbag configurations, with two different soilbag sizes, staggered or aligned arrangements, and varying seepage path lengths (soilbag wall heights)

\section{RESULTS AND DISCUSSION}

\subsection{Permeability coefficients and gradient ratios for soil- fabric systems}

As shown in Figure 3a, the permeability coefficients of the soil-fabric systems with different hydraulic gradients changed with time. At the hydraulic gradient of $i=4$, the permeability coefficient increased slowly, and as $i$ increased from 7 to 11 , the permeability coefficient gradually stabilized, indicating that the fabric and soil particles gradually developed a filter structure. When $i$ increased directly to 11 , the permeability coefficient of the system decreased by $77.99 \%$. This decrease was caused by the sudden increase in seepage flow, which caused the soil pressure to increase and led to gradual movement and rearrangement of adjacent soil. Local soil particles then formed through compaction, which caused the permeability coefficient for the entire system to decrease with time. At the same time, fine particles at the bottom entered the fabric with a certain seepage force. Fine particles trapped within the fabric pore structure then caused the fabric permeability coefficient to decrease.

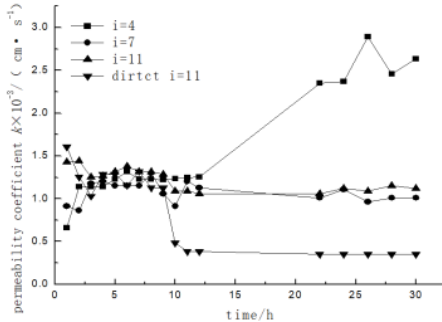

(a) Permeability coefficient

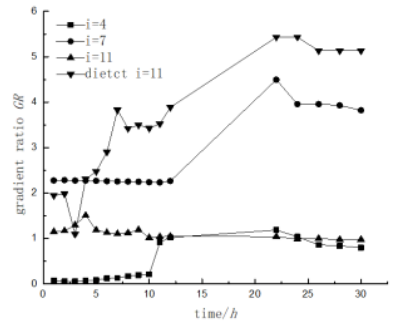

(b) GR
Figure 3. Permeability coefficients and $G R$ vs time for soiltextile systems with different hydraulic gradients

As shown in Figure 3b, the $G R$ of the soil-fabric systems with different hydraulic gradients changed with time. At the hydraulic gradient of $i=4$, the $G R$ increased from 0.055 to 1.19 , stabilizing at 0.8 after $24 \mathrm{~h}$. At the beginning of the test, there was more erosion of fine particle soil, causing the filtration performance to reduce. After $20 \mathrm{~h}$ of filtration performance enhancement, the fabric filter layer and soil particles formed an arch structure, leading to a stable filter system that ensured smooth seepage. After this stabilization, large losses of soil particles did not happen again. At $i=7$, during the early stage of the experiment, the $G R$ was $<3$, but after $16 \mathrm{~h}, G R$ increased to 4.5 and filtration performance worsened. This was mainly because soil particles entered the fabric pore structure. Reduction of the effective aperture and disorder of the non-woven fiber arrangement caused the fabric to be more likely to intercept soil particles. When $i$ increased gradually to 11 , the $G R$ tended to be stable. When $i$ increased directly to 11 , the $G R$ filtration performance was reduced after 
$6 \mathrm{~h}$, indicating that the hydraulic gradient increased directly in a short period of time and thus reduced the fabric siltation performance.

Soil quantities per unit area $(\mu)$ and leaked soil contents at different hydraulic gradients are presented in Table 3. For black polypropylene specimens in the first test with $i$ increasing gradually to 4,7 , and 11 , the fabric soil content $\mu$ was lower than in the second test with $i$ increasing directly to 11. The second test indicates that a one-time exertion of a larger hydraulic gradient causes the water flow rate to increase. Meanwhile, the seepage force increased, the soil structure had larger adjustments, soil erosion decreased with the slightly larger fine particles, and the smaller fine particles washed out of the fabric. Therefore, the amount of soil remaining in the fabric was slightly less than in the first test, while the amount of soil behind the fabric and water leakage both increased.

Table 3. Amount of soil in the geotextiles at different hydraulic gradients

\begin{tabular}{cccc}
\hline $\begin{array}{c}\text { Increase mean of } \\
i\end{array}$ & $\begin{array}{c}\mu \\
\mathrm{g} \cdot \mathrm{cm}^{-3}\end{array}$ & $\begin{array}{c}\text { Leakage } \\
/ \mathrm{g}\end{array}$ & $\begin{array}{c}\text { Back of fabric } \\
\text { leakage }\end{array}$ \\
\hline A $i=4,7$, and 11 & 0.057 & 0.05 & a little \\
& 35 & & little more \\
B $i=11$ & 0.046 & 1.12 & increase \\
& 61 & & \\
B compared to A & decrease & increase & \\
\hline
\end{tabular}

\subsection{Permeability coefficient of the soilbag wall}

3.2.1 Permeability coefficients of soilbag walls with different layering

The measured permeability [23] coefficients are given in Table 4 . The smallest permeability coefficient of $1.34 \times 10^{-3}$ $\mathrm{cm} \cdot \mathrm{s}^{-1}$ was found for M6, which had small bags on top and large bags on the bottom with staggered joints. The largest permeability coefficient of $1.45 \times 10^{-2} \mathrm{~cm} \cdot \mathrm{s}^{-1}$ was found for M7, which had all small bags lined up. The value for M7 was nearly 10 times larger than that for $\mathrm{M} 6$, and $10^{3}$ times larger than that for undisturbed soil of $4.63 \times 10^{-5} \mathrm{~cm} \cdot \mathrm{s}^{-1}$. The permeability coefficients values followed the order M6 $<$ M3 $<$ M8 $<$ M1 $<$ M7.

Experimental results indicate that wall seepage through the soilbags depends on the gaps between the bags, with more gaps causing larger permeability coefficients. The smaller bags had a larger permeability coefficient because even though the gap sizes were smaller, there were a larger number of gaps. Additionally, staggered joints with their overlapping structure reduced the permeability coefficient, since the seepage path variable length is longer and energy loss is increased. The permeability coefficients of the soilbags ranged from $1.34 \times 10^{-}$ ${ }^{3}$ to $1.45 \times 10^{-2} \mathrm{~m} \cdot \mathrm{s}^{-1}$ for the different configurations, indicating that arrangement affects the permeability coefficient ratio as much as $90.75 \%$.

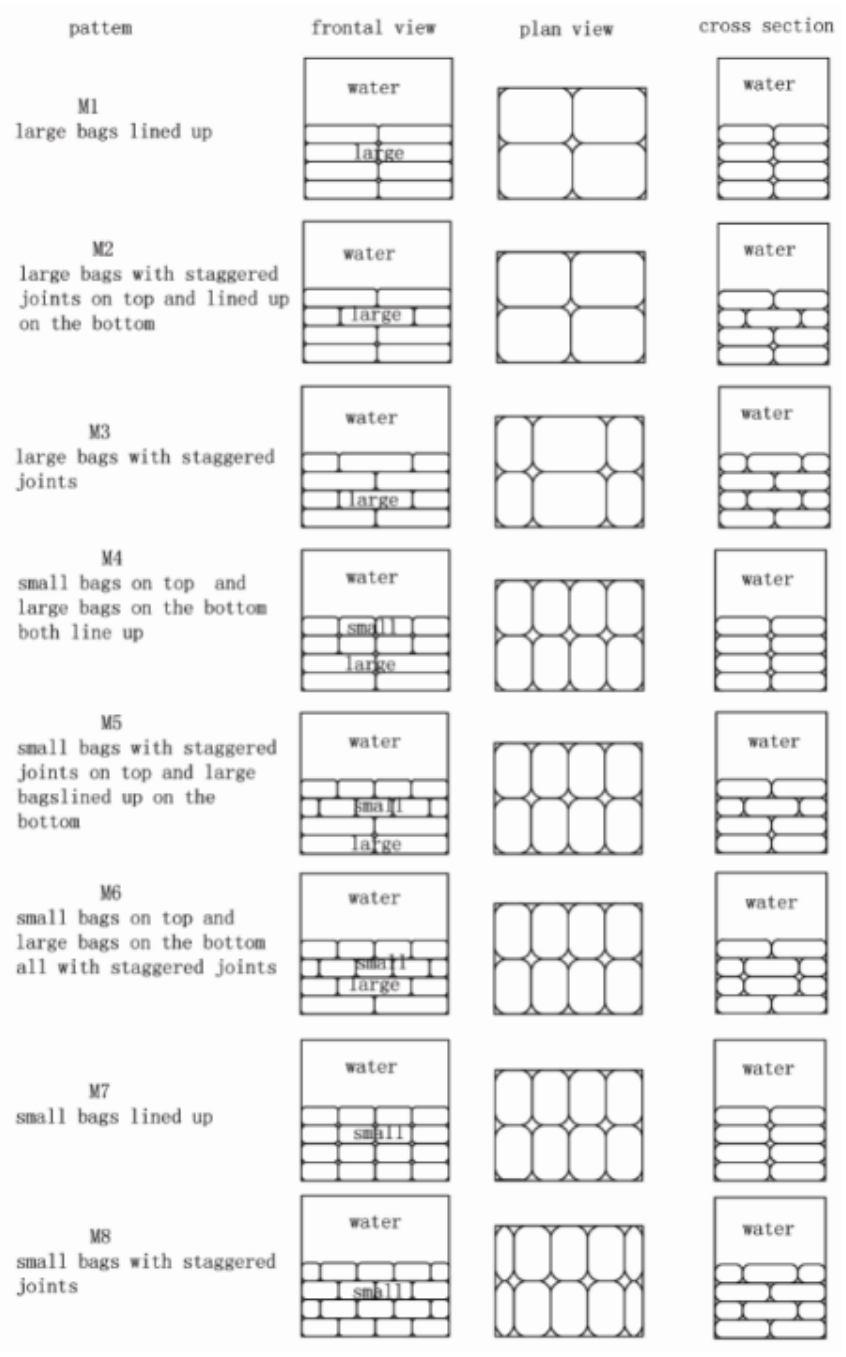

Figure 4. Model configurations used in the permeability tests 
Gaps between the soilbags disperse the water pressure. Although the permeability coefficients of soilbags arranged with staggered joints was lower than that for lined up joints, the staggered joints produced better interlocking, which enhanced hydraulic stability in the system. Water flow in gaps between the soilbags determines the permeability coefficient of the entire system. Larger gaps produced larger permeability coefficients, which is consistent with the research conclusions of Recio(2008). Flow is affected by different shapes and sizes in the winding channel. In a hypothetical experiment, instead of actual water flow, the hypothetical flow resistance in an arbitrary volume structure is used. The advantage of this approach is that any non-continuous flow can be analyzed as a continuous flow for theoretical exploration.

Table 4. Permeability test results

\begin{tabular}{|c|c|c|c|c|c|c|c|}
\hline Model & $\begin{array}{l}\text { Head, } H \\
\quad / \mathrm{cm}\end{array}$ & $\begin{array}{l}\text { Hydraulic } \\
\text { gradient, } i\end{array}$ & $\begin{array}{l}\text { Flow, } Q \\
/ \mathrm{mL} \cdot \mathrm{s}^{-1}\end{array}$ & $\begin{array}{c}\text { Permeability } \\
\text { Coefficient, } k \\
/ \mathrm{cm} \cdot \mathrm{s}^{-1} \\
\end{array}$ & $\begin{array}{c}\text { Average value } \\
\text { of } k \\
/ \mathrm{cm} \cdot \mathrm{s}^{-1}\end{array}$ & $\begin{array}{c}\text { Combined } \\
\text { layers } k \\
/ \mathrm{cm} \cdot \mathrm{s}^{-1} \\
\end{array}$ & $\begin{array}{l}\text { Increasing multiple } \\
\text { of } k\end{array}$ \\
\hline \multirow{3}{*}{ M1 } & 55 & 1.3 & 68.83 & $1.23 \times 10^{-2}$ & \multirow{3}{*}{$1.17 \times 10^{-2}$} & \multirow{3}{*}{$9.22 \times 10^{-5}$} & \multirow{3}{*}{0.992} \\
\hline & 80 & 1.9 & 102.86 & $1.26 \times 10^{-2}$ & & & \\
\hline & 105 & 2.5 & 110.30 & $1.03 \times 10^{-2}$ & & & \\
\hline \multirow{3}{*}{ M2 } & 55 & 1.6 & 25 & $3.52 \times 10^{-3}$ & \multirow{3}{*}{$3.33 \times 10^{-3}$} & \multirow{3}{*}{$9.13 \times 10^{-5}$} & \multirow{3}{*}{0.973} \\
\hline & 80 & 2.4 & 35.48 & $3.44 \times 10^{-3}$ & & & \\
\hline & 105 & 3.1 & 41.07 & $3.03 \times 10^{-3}$ & & & \\
\hline \multirow{3}{*}{ M3 } & 55 & 1.7 & 16.67 & $2.21 \times 10^{-3}$ & \multirow{3}{*}{$2.09 \times 10^{-3}$} & \multirow{3}{*}{$9.06 \times 10^{-5}$} & \multirow{3}{*}{0.957} \\
\hline & 80 & 2.5 & 23.59 & $2.15 \times 10^{-3}$ & & & \\
\hline & 105 & 3.3 & 27.49 & $1.91 \times 10^{-3}$ & & & \\
\hline \multirow{3}{*}{ M4 } & 55 & 1.3 & 36.66 & $6.53 \times 10^{-3}$ & \multirow{3}{*}{$6.23 \times 10^{-3}$} & \multirow{3}{*}{$9.2 \times 10^{-5}$} & \multirow{3}{*}{0.985} \\
\hline & 80 & 1.9 & 50.29 & $6.16 \times 10^{-3}$ & & & \\
\hline & 105 & 2.4 & 64.36 & $6.01 \times 10^{-3}$ & & & \\
\hline \multirow{3}{*}{ M5 } & 55 & 1.4 & 10.17 & $1.69 \times 10^{-3}$ & \multirow{3}{*}{$1.45 \times 10^{-3}$} & \multirow{4}{*}{$8.97 \times 10^{-5}$} & \multirow{3}{*}{0.938} \\
\hline & 80 & 2 & 14.22 & $1.62 \times 10^{-3}$ & & & \\
\hline & 105 & 2.6 & 11.87 & $1.03 \times 10^{-3}$ & & & \\
\hline \multirow{3}{*}{ M6 } & 55 & 1.3 & 8.33 & $1.42 \times 10^{-3}$ & \multirow{3}{*}{$1.34 \times 10^{-3}$} & & \multirow{3}{*}{0.933} \\
\hline & 80 & 2 & 9.07 & $1.06 \times 10^{-3}$ & & \multirow[t]{2}{*}{$8.95 \times 10^{-5}$} & \\
\hline & 105 & 2.5 & 17.19 & $1.53 \times 10^{-3}$ & & & \\
\hline \multirow{3}{*}{ M7 } & 55 & 1.7 & 120 & $1.64 \times 10^{-2}$ & \multirow{3}{*}{$1.45 \times 10^{-2}$} & \multirow{3}{*}{$9.23 \times 10^{-5}$} & \multirow{3}{*}{0.994} \\
\hline & 80 & 2.4 & 130.64 & $1.23 \times 10^{-2}$ & & & \\
\hline & 105 & 3.2 & 206.56 & $1.48 \times 10^{-2}$ & & & \\
\hline \multirow{3}{*}{ M8 } & 55 & 1.3 & 30.17 & $5.37 \times 10^{-3}$ & \multirow{3}{*}{$5.19 \times 10^{-3}$} & \multirow{3}{*}{$9.18 \times 10^{-5}$} & \multirow{3}{*}{0.982} \\
\hline & 80 & 1.9 & 42.94 & $5.26 \times 10^{-3}$ & & & \\
\hline & 105 & 2.4 & 52.8 & $4.93 \times 10^{-3}$ & & & \\
\hline
\end{tabular}

3.2.2 Calculating the equivalent permeability coefficients for soil-soilbag slopes

The ShengLi ditch slope in the Qingtongxia irrigation area of Ningxia town was selected as the experimental zone. Groundwater seepage was assumed to occur through a double medium slope protection of undisturbed soil and soilbags, as shown in Figure 5a. The ditch slope revetment height $(H)$ was $1.8 \mathrm{~m}$, the slope was $1: 1.5$, and $d_{l} \approx d_{2} \approx 3 \mathrm{~m}$. This case involved a mutation permeability interface with oblique flow, as shown in Figure 5b, according to:

$\tan \theta_{1}=\frac{v_{1 t}}{v_{1 n}}, \tan \theta_{2}=\frac{v_{2 t}}{v_{2 n}}$

Any point in the interface must meet the conditions $H_{1}=H_{2}$ and $v_{l n}=v_{2 n}$, so that

$\frac{\tan \theta_{1}}{\tan \theta_{2}}=\frac{v_{1 t}}{v_{2 t}}=\frac{-k_{1} \frac{\partial H_{1}}{\partial x}}{-k_{2} \frac{\partial H_{2}}{\partial x}}$,

which can be further simplified to

$\frac{\tan \theta_{1}}{\tan \theta_{2}}=\frac{k_{1}}{k_{2}}$ where $H_{1}$ and $H_{2}$ are the water heads for the soil and soilbags; $v_{l}$ and $v_{2}$ are the seepage velocities; $v_{l n}, v_{2 n}, v_{l t}$, and $v_{2 t}$ are the normal and tangential velocities of $v_{l}$ and $v_{2} ; \theta_{l}$ and $\theta_{2}$ are the angles between the interface and either side of the face streamline; and $k_{1}$ and $k_{2}$ are coefficients of permeability for the soil and soilbags layer.

On either side of the interface, the permeability coefficient of the soil layer was $4.63 \times 10^{-5} \mathrm{~cm} \cdot \mathrm{s}^{-1}$, while that of the soilbags was $1.45 \times 10^{-2} \mathrm{~cm} \cdot \mathrm{s}^{-1}$, a difference of 3 orders of magnitude. From Formula (3), the value ranges of $\theta_{1}$ and $\theta_{2}$ were also wide, and the deviation degree after seepage through the interface was large. The seepage pressure direction was offset in the direction of gravity, which was conducive to slope stability, as shown in Figure 5a. The flow of water through the soil and soilbag layers was same, i.e., $q_{1}=q_{2}=q$. For different head losses and hydraulic gradients, the total head loss, $\Delta H$, is equal to the sum of individual head losses, $\Delta H_{i}$. Therefore, for each layer:

$q=k_{i} H \frac{\triangle H_{i}}{d_{i}}, \Delta H_{\mathrm{i}}=\frac{d_{i} q}{k_{i} H}$

The equivalent permeability coefficient of the slope is thus 


$$
k=\frac{\sum_{\mathrm{i}=1}^{n} d_{i}}{\sum_{i=1}^{n} \frac{d_{i}}{k_{i}}}
$$

From this, the permeability coefficients of the soil-soilbag slope protection could be derived.

$$
k=\frac{k_{1} k_{2}\left(d_{1}+d_{2}\right)}{d_{1} k_{2}+d_{2} k_{1}}
$$

where $k_{1}$ and $k_{2}$ are the permeability coefficients for the soilsoilbag slope, and $d_{1}$ and $d_{2}$ are the permeable zone width. $H$ is the height of slope protection.



(a) Penetration schematic

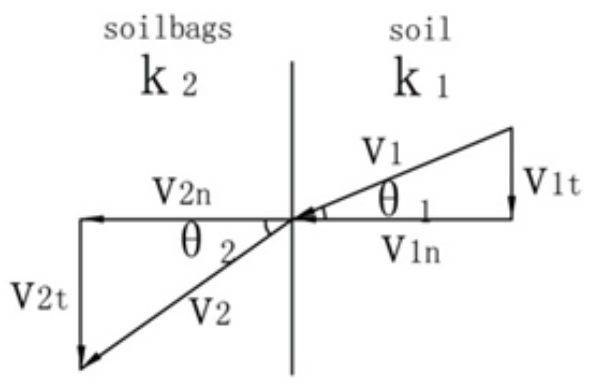

(b) Refraction flow

Figure 5. Penetration of a double medium revetment and seepage refraction

The calculation results of the equivalent permeability coefficients for different soilbag arrangements are given in Table 4 . The calculated permeability coefficient was larger than the permeability coefficient of the soil itself, increasing nearly $100 \%$. The seepage pressure generated by the flow could be calculated as:

$f=\gamma J, \quad J=\frac{v}{k}$, that is $f=\gamma \frac{v}{k}$

where $f$ is the seepage pressure; $\gamma$ is the slope density; $v$ is the seepage speed; $J$ is the hydraulic gradient; and $k$ is the permeability coefficient of the slope.

Formula (6) indicates that, for a given seepage velocity and density slope, the permeability pressure is inversely proportional to the permeability coefficient. The permeability coefficients for the eight soil-soilbag arrangements were all nearly 2 times that of the soil itself. Pressure-produced seepage decreased nearly $50 \%$, which was beneficial for slope stability. With an increasing permeability coefficient, water discharge from the slope was easier with decreasing water levels. The seepage pressure decreased quickly, so that the safety factor of the slope decreased modestly. In contrast, if the permeability coefficient decreased, the water would not discharge quickly enough, and the seepage pressure would produce high shear forces in the slope body, causing a landslide.

\section{CONCLUSION}

Through hydraulic gradient ratio tests of soil-soilbag systems using two different soilbag sizes and eight soilbag arrangements, the permeability coefficients were determined and the following can be concluded.

(1) When the hydraulic gradient increased directly, the permeability coefficient of the soil-fabric system decreased, $G R$ increased, the filtration performance worsened, the soil content per unit area of fabric $(\mu)$ decreased, and soil leakage increased.

(2) The permeability coefficient of the soil was $4.63 \times 10^{-5}$, while that of the soil-fabric was $1.02 \times 10^{-3}$, and that of the soilbag structure was $1.45 \times 10^{-2} \mathrm{~cm} \cdot \mathrm{s}^{-1}$. The permeability mainly depended on the gaps between soilbags.

(3) The soilbag arrangement clearly affected the permeability coefficient of the structure, with values in the order $\mathrm{M} 6<\mathrm{M} 3<\mathrm{M} 8<\mathrm{M} 1<\mathrm{M} 7$. Smaller bags had larger permeability coefficients. The influence of the soilbag arrangement on the permeability coefficient ratio was as high as $90.75 \%$.

(4) The equivalent permeability coefficient for a soilsoilbags system increased nearly $100 \%$ from that of the soil itself, while the seepage pressure reduced nearly $50 \%$. This combination effectively improved the stability of the slope protection.

Due to the limited test conditions, this experiment makes a preliminary determination of the actual permeability coefficients for soilbag structures. This work provides a reference basis for use in the actual construction of soilbag support structures. Future experiments will continue to study the stability of soilbag slope protection during seepage for practical engineering application.

\section{ACKNOWLEDGMENT}

This work was supported by the national natural science fund project (41462010); Ningxia college scientific research project (NGY2016244); Ningxia university graduate student innovation project funding (GIP201635).

\section{REFERENCE}

[1] Recio J, Oumeraci H. (2009). Peocesses affecting the hydraulic stability of coastal revetments made of geotextile sand containers. Coastal Engineering 56: 260284. http://dio.org/10.1016/j.coastaleng.2008.09.006

[2] Recio J, Oumeraci H. (2007). Effect of deformations on the hydraulic stability of coastal structures made of geotextile sand containers. Geotextiles and Geomembranes. 25: 278-292. http://dio.org/10.1016/j.geotexmem. 2007.02.006 
[3] Koerner RM. (2000). Emerging and future developments of selected geosynthetic applications. Journal of Geotechnical and Geoenvironmental Engineering 126(4): 291-306.

[4] Corbella S, Stretch DD. (2012). Geotextile sand filled containers as coastal defence: South African experience. Geotextiles and Geomembranes 35: 120-130. http://dx.doi.org/10.1016/j.geotexmem.2012.09.004

[5] Yasuhara K, Recio-Molina J. (2007). Geosynthetic-wrap around revetments for shore protection. Geotextiles and Geomembranes 25: 221-232. http://dio.org/10.1016/j.geotexmem.2007.02.004

[6] Vahedifard F, Shahrokhabadi S, Leshchinsky D. (2016). Geosynthetic-reinforced soil structures with concave facing profile. Geotextiles and Geomembranes 44: 358$365 . \quad \mathrm{http} / / / \mathrm{dx}$.dio.org/10.1016/j.geotexmem. 2016.01.004

[7] Bai ZF, Li GL, Xiang LI, Zhang PX, Liu P, Gao X, Zhu SJ. (2014). Stability of terraced ridges using polypropylene geotextile bags. Journal of Northwest A\&F Univcrsity (Nat. Sci. Ed) 42(4): 157-164. http://dx.doi.org/10.13207/j.cnki.jnwafu.2014.04.024.ht $\mathrm{ml}$

[8] Li GL, Gao X, Liu X. (2015). The main forms and stability of terraced walls build with polypropylene geotextile bags. Journal of China Agricultural University 20(2): 201-206. http://dx.doi.org/10.11841/j.issn.10074333.2015.02.25

[9] Li GL, Liu LN, Zhang T. (2015). Benefits of terraced fields ridges built by polypropylene geotextile bags. Soil and Water Conservation in China 8: 70-72. http://dx.doi.org/10.14123/j.cnki.swcc.2015.0231

[10] Korkut R, Martinez EJ, Morales R, Ettema R, Barkdoll B. (2007). Geobag performance as scour counter measure for bridge abutments. Journal of Hydrologic Engineering 13(4): 431-439. https://doi.org/10.1061/(ASCE)07339429(2007)133:4(431)

[11] Akter A, Pender G, Wright G, Crapper M. (2013). Performance of a Geobag Revetment. I: Quasi-Physical Modeling. Journal of Hydraulic Engineering 139(8): 865-876. http://dx.doi.org/10.1061/(ASCE)HY.19437900.0000735

[12] Akter A, Pender G, Wright G, Crapper M. (2013). Performance of a geobag revetment II: numerical modeling. Journal of Hydraulic Engineering 139(8): 877885. http://dx.doi.org/10.1061/(ASCE)HY.1943-
7900.0000724.

[13] Li Z, Liu SH, Wang LJ. (2013). Experimental study of frost heave and thawing settlement of soilbags under different freeze-thaw cycles. Rock and Soil Mechanic 34(9): 2541-2545. http://10.16285/j.rsm.2013.09.018.

[14] Zhang YY. (1988). Causes of slope failure of drainage ditches and its prevention. Journal of Hohai University 16(2): 70-76

[15] Tang L, Tang XW, She W. (2013). Influence of uniaxial tensile strain on filtration characteristics of geotextiles. Chinese Journal of Geotechnical Engineering 35(4): 785788 .

[16] Chen L, Yi HQ, Xu Qi. (2006). The study of the structure stability simulated tests in soil-geotextile filtration system. Journal of Hydroelectric Ingineering 25(4): 117121.

[17] Shu YM. (2002). Application of needle-punched geotextile of silt as reversed filter. Shuili Xuebao 11: 9599. http://dx.doi.org/10.13243/j.cnki.slxb.2002.11.017

[18] Hu LW. (2002). Experimental study on filter geotextiles applied in Shenzhen River project. Chinese Journal of Geotechnical Engineering 24(3): 351-355.

[19] Shan HY, Wang WL, Chou TC, (2001). Effect of boundray conditions on the hydraulic behavior of geotextile filtration system. Geotextiles and Geomembranes 19(7): 509-527.

[20] Recio J, Oumeraci H. (2008). Hydraulic permeability of structures made of geotextile sand containers: Laboratory tests and conceptual model. Geotextiles and Geomembranes 26(9): 473-487. http://dx.doi.org/10.1016/j.geotexmen.2008.05.006.

[21] Liu SH, Bai FQ, Wang YS, Wang S. (2013). Treatment for txpansive soil channel slope with soilbags. Joureal of Aerosoace Engineering 26: 657-666. http://dx.doi.org/10.1061/(ASCE)AS.19435525.0000198.

[22] Goncalves JC, Caetano Vasques N, Silva C, Paccola E, Schmidt Filho E, Ueda Yamaguchi N, Aparecida Andreazzi M, Gasparotto F. (2018). Influence of the application of filter cake on soil chemical characteristics. Chemical Engineering Transactions 65: 775-780. http://dx.doi.org/10.3303/CET1865130

[23] Fang K, Zhou H, Lu Z. (2018). Research on optimization of drill hole gas pre-drainage process in low permeability outburst coal seam. Chemical Engineering Transactions 66: 667-672. http://dx.doi.org/10.3303/CET1866112 